\title{
Advances and challenges in the implementation of a comprehensive fire management policy in the Bolivarian Republic of Venezuela
}

\author{
Miguel Alejandro Matany Luque ${ }^{* 1}$, Elias Guillermo León ${ }^{1}$, José Gregorio Biskis Ardilal, Germán \\ Gutiérrez ${ }^{1}$, Bibiana Alejandra Bilbao ${ }^{2}$, Roberto Rivera-Lombardi ${ }^{3}$,Adriana Millán ${ }^{1,4}$
}

\footnotetext{
${ }^{1}$ Cuerpo de Bomberos Forestales, Instituto Nacional de Parques (INPARQUES), (*autor de contacto: mmatany@yahoo.com);

${ }^{2}$ Universidad Simón Bolívar,

${ }^{3}$ Universidad Central de Venezuela, Caracas, Venezuela y

${ }^{4}$ Centro de Investigación y Transferencia Rafaela, Universidad Nacional de Rafaela - CONICET, Argentina
}

\begin{abstract}
The National Park System (NPS) of the Bolivarian Republic of Venezuela comprehends 43 National Parks, 37 Natural Monuments and 65 Recreation Parks, which represent $23 \%$ of the national territory. This system preserves the springs of $80 \%$ of the water basins that supply water to the population, including the Caroní river basin, which generates $70 \%$ of the country's electricity. Climate change scenarios mean an increase in temperatures, a worsening of drought higher severity of vegetation fires, and extended fire seasons. Fire vulnerability of NPS ecosystems, which includes fire-sensitive vegetation such as cloud and evergreen forests and high Andean wetlands as well as the rural-urban interface, has posed new challenges. We were forced to rethink beyond formerly established fire suppression and combat models and develop new and more effective fire management strategies nationwide. Since 2014, Integrated Fire Management (IFM) initiatives were considered as part of new management policies promoted by the National Forest Fire Department. This process started with the inclusion of community members, their local traditional knowledge of fire management, and scientific findings, to reduce effectively the annually burnt area, especially in locations with fire-sensitive vegetation. Likewise, since April 2009, an ambitious human talent reinforcement plan began its implementation, through "Special Training Plans" offered by National Experimental University of Security, to reach the goal of 10,000 new firefighters troop's formed at the national level, under the principles of the IFM. Additionally, it has already been envisaged the need to strengthen multimodal warning systems, fire monitoring by remote sensors, early detection and first response to forest fires, inter-agency coordination of a shared logistic support network and the development of a permanent evaluation and adjustment mechanism. Of plans, protocols and procedures with leading and equitable participation of researchers, local communities and officials under the principles of intercultural, joint effort and mutual respect of all its members.
\end{abstract}

Keywords: Integrated Fire Management, Forest fire management policies, forest firefighters, significant fire reduction, National Park System (NPS), Venezuela. 